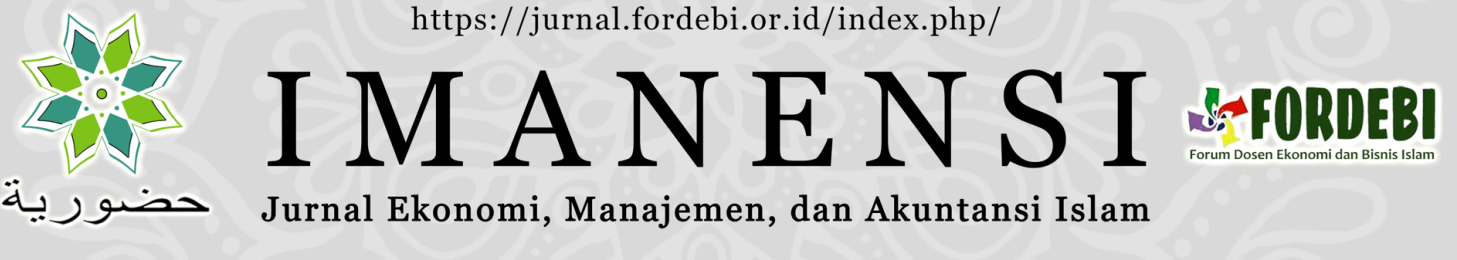

\title{
ISLAMIC SOCIAL REPORTING DAN ISLAMIC CORPORATE GOVERNANCE SEBAGAI PENENTU NILAI PERUSAHAAN
}

\author{
Heni Febriyantia,1, Ari Kamayantib,2*, Nur Indah Riwajantic,3 \\ a,b,c Politeknik Negeri Malang, Jl. Soekarno Hatta No.9, Malang, Jawa Timur, 65141, Indonesia \\ 1febriyantiheni1@gmail.com; ${ }^{2}$ kamayanti.ari@gmail.com*; ${ }^{3}$ nurindah12@gmail.com \\ *Corresponding author
}

\begin{abstract}
INFO ARTIKEL
IMANENSI

Volume 7

Nomor 1

Halaman 1-12

Malang, Maret 2022

ISSN: 2339-1847

e-ISSN: 2683-9968

Kronologi Artikel:

Tanggal Masuk:

26 Agustus 2021

Tanggal Revisi:

2 Maret 2022

Tanggal Diterima:

2 Maret 2022

Kata Kunci:

Islamic Corporate Governance; Islamic Social Reporting;

Kinerja Keuangan;

Nilai Perusahaan.

Keywords:

Company's Value;

Financial Performance;

Islamic Corporate Governance;

Islamic Social Reporting.

Abstrak: Islamic Social Reporting dan Islamic Corporate Governance Penentu Nilai Perusahaan. Penelitian ini bertujuan untuk mengetahui pengaruh pengungkapan Islamic Social Reporting dan Islamic Corporate Governance terhadap nilai perusahaan melalui kinerja keuangan. Penelitian ini menggunakan metode kuantitatif dengan pendekatan explanatory. Hasil penelitian menunjukkan bahwa Islamic Social Reporting dan Islamic Corporate Governance berpengaruh signifikan terhadap kinerja keuangan. Sedangkan Islamic Social Reporting dan Islamic Corporate Governance berpengaruh tidak signifikan terhadap nilai perusahaan. Kinerja keuangan berpengaruh positif signifikan terhadap nilai perusahaan dan tidak dapat memediasi pengaruh antara Islamic Social Reporting dan Islamic Corporate Governance pada nilai perusahaan.

Abstract: Islamic Social Reporting and Islamic Corporate Governance on Company's Value through Financial Performance. This study aimed to examine the impact of Islamic Social Reporting and Islamic Corporate Governance disclosures on company's value through financial performance. This study was quantitative method with explanatory approach. The result of this study indicated that Islamic Social Reporting and Islamic Corporate Governance had a significant effect on financial performance. However, Islamic Social Reporting and Islamic Corporate Governance had insignificant effects on company's value. The financial performance had a significant positive effect on company's value and may not be an intermediary for the effects of Islamic Social Reporting and Islamic Corporate Governance on company's value.
\end{abstract}

Disitasi sebagai: Febriyanti, H., Kamayanti, A., \& Riwajanti, N.I. (2022). Islamic Social Reporting dan Islamic Corporate Governance sebagai Penentu Nilai Perusahaan. IMANENSI: Jurnal Ekonomi, Manajemen, dan Akuntansi Islam, 7(1), 1-12. https://doi.org/ 10.34202/imanensi.7.1.2022.1-12.

\section{PENDAHULUAN}

Pesatnya perkembangan yang terjadi pada perbankan syariah akibat dicetuskannya UU No. 21 Tahun 2008 tentang perbankan syariah, memunculkan tantangan baru yang harus dihadapi oleh Lembaga perbankan syariah (Kamla, 2009b). Pasalnya, hingga saat ini market share industri keuangan RI masih dikuasai oleh perbankan konvensional, yaitu sebesar 93,89\%. Sementara, perbankan syariah hanya sisanya, yaitu $6.11 \%$ (tirto.id, 2020). Kebijakan terkait perbankan syariah 
masih berkutat pada kemampuan lembaga keuangan syariah meningkatkan kinerjanya untuk tujuan jangka pendek dan memaksimalkan nilai perusahaannya untuk tujuan jangka panjang dalam rangka menarik pelanggan ataupun investor sehingga dapat memenangkan persaingan. Terkait dengan kebijakan ini, terdapat kritikan atas orientasi perbankan syariah yang tak jauh berbeda dengan perbankan non syariah yaitu penumpukan modal selaras dengan ideologi kapitalisme (Kamla, 2009a).

Memaksimalkan kesejahteraan pemilik atau shareholders merupakan tujuan didirikannya suatu perseroan yang dapat dicapai dengan menaikkan nilai perusahaan (Setiawati \& Lim, 2018). Kinerja keuangan dan nilai perusahaan dapat dijadikan sebagai gambaran bagi investor untuk menilai sejauh mana tingkat keberhasilan perusahaan. Besarnya tuntutan dan tantangan tersebut menempatkan Corporate Social Responsibility (CSR) dan Good Corporate Governance (GCG) sebagai praktik yang penting, tidak terkecuali lembaga keuangan syariah. Seiring dengan semakin berkembangnya lembaga-lembaga yang menerapkan prinsip-prinsip syariah seperti halnya pada Bank Umum Syariah, mulai dikembangkan pula konstruksi tanggung jawab terhadap sosial dan tata kelola perusahaan yang menjalankan bisnis dengan berpegang pada pedoman syariat Islam yaitu disebut sebagai Islamic Social Reporting atau yang disingkat dengan ISR dan Islamic Corporate Governance yang disingkat dengan ICG.

ISR sebagai turunan dari konsepsi CSR menjadi bentuk pertanggungjawaban sosial perusahaan kepada masyarakat dan terutama Allah SWT (Abadi, Mubarok, \& Sholihah, 2020). Pengungkapan ISR juga menjadi suatu siasat yang dapat diterapkan oleh lembaga perbankan syariah untuk memenangkan persaingan dan esensial bagi kinerja dan nilai perbankan syariah dikarenakan investor cenderung memilih untuk menanamkan modalnya di entitas yang melakukan aktivitas CSR. Disamping itu, agar suatu perusahaan dapat tumbuh dengan sehat dan baik untuk menjaga eksistensi perusahaan, lebih-lebih bagi institusi keuangan dapat di implementasikan melalui penerapan GCG (Nugroho, 2015). ICG sebagai bentuk dari pengimplementasian GCG yang mengacu pada syariat Islam diharapkan mampu memberikan proteksi dan jaminan kepada stakeholders guna meminimalkan tindakan-tindakan yang dapat merugikan perusahaan demi kepentingan pribadi manajemen. Melalui pengimplementasian ICG diharapkan mampu berdampak terhadap citra baik dan kepercayaan nasabah yang juga berimplikasi pada peningkatan pangsa pasar industri perbankan syariah (Junusi, 2012). Artinya, hal ini juga menjadi sinyal positif bagi lembaga keuangan agar dapat memaksimalkan nilainya.

Berdasarkan hasil riset terdahulu, ICG memberikan pengaruh yang cukup signifikan positif terkait kinerja keuangan perbankan syariah, sementara ISR berdampak negatif terhadap kinerja perbankan syariah (Ananda \& NR, 2020). Namun, riset sejenis di Indonesia menunjukkan bahwa pengungkapan ISR berdampak positif dan signifikan terhadap ROA serta ICG tidak punya pengaruh pada kinerja keuangan (Mardani dkk, 2019; Ibrahim dkk, 2019), walau pada riset yang berbeda pengungkapan ICG dan ISR memberikan pengaruh terhadap nilai perusahaan (Ibrahim \& Muthohar, 2019). Kinerja keuangan dinilai bisa memediasi pengaruh pengungkapan ISR pada nilai bank syariah (Dianawati, 2016; Efendi, 2020). Namun, hasil penelitian lain membuktikan bahwasanya kinerja keuangan tidak bisa menjadi mediator pengaruh pengungkapan ISR pada niai perusahaan (Utami dkk, 2020; Suryani dkk, 2020). Sedangkan ICG mampu mempengaruhi nilai perusahaan melalui kinerja keuangan dan inkonsiten dengan hasil penelitian yang menunjukkan bahwa kinerja keuangan tidak bisa menjadi perantara pengaruh 
pengungkapan ICG pada nilai bank syariah (Dianawati dkk, 2016; Nursyarifah, 2017). Berdasarkan inkonsistensi hasil penelitian sebelumnya, maka peneliti tertarik untuk melakukan penelitian yang bertujuan untuk mengetahui pengaruh pengungkapan ISR dan ICG terhadap nilai perusahaan melalui kinerja keuangan baik secara langsung ataupun tidak langsung pada Bank Umum Syariah periode 2015-2019.

\section{METODE}

Metode penelitian yang digunakan adalah metode penelitian kuantitatif dengan pendekatan explanatory research yang dilakukan pada Bank Umum Syariah di Indonesia tahun 2015-2019. Data yang digunakan adalah data sekunder yang berupa annual report Bank Umum Syariah yang diperoleh melalui website resmi masing-masing Bank Umum Syariah yang diperoleh dengan metode dokumentasi. Pemilihan sampel dilakukan dengan metode purposive sampling dengan kriteria yaitu: (1) Bank Umum Syariah yang beroperasi di Indonesia (2) Bank Umum Syariah yang konsisten menyajikan annual report pada periode penelitian (3) Bank Umum Syariah yang konsisten menghasilkan laba selama periode penelitian (4) Bank Umum Syariah yang mengungkapkan informasi mengenai ISR dan ICG dalam annual report. Dari kriteria tersebut diperoleh sampel sebanyak 10 Bank Umum Syariah dari total populasi sebanyak 14 Bank Umum Syariah, sehingga dalam periode 2015-2019 terdapat 50 data yang diteliti.

Teknik analisis data yang digunakan yakni analisis regresi berganda untuk menguji pengaruh variabel independen terhadap variabel dependen dan analisis jalur untuk mengetahui pengaruh tidak langsung dari variabel mediasi. Sebelum dilakukan analisis regresi dan analisis jalur, maka terlebih dahulu dilakukan analisis statistik deskriptif, uji korelasi, dan uji asumsi klasik. Berikut adalah persamaan regresi dari analisis data pada penelitian ini:

$$
\begin{aligned}
& Z=\rho z x 1 X_{1}+\rho z x 2 X_{2}+\rho z \varepsilon 1 \ldots \ldots \ldots \ldots . .(1) \\
& Y=\rho y x 1 X_{1}+\rho y x 2 X_{2}+\rho y \varepsilon 1 \ldots \ldots \ldots \ldots .(2) \\
& Y=\rho y x 1 X_{1}+\rho y x 2 X_{2}+\rho y z+\rho y \varepsilon 2 \ldots(3)
\end{aligned}
$$

Variabel dependen pada penelitian diwakili oleh nilai perusahaan. Rasio Tobin's $\mathrm{Q}$ dipilih untuk tujuan melakukan pengukuran terhadap nilai perusahaan. Apabila rasio ini melebihi satu, maka membuktikan bahwa laba yang dihasilkan perusahaan memberikan nilai lebih dibandingkan dengan investasi yang dikeluarkan. Apabila rasio ini lebih kecil dari satu, maka mengindikasikan bahwa investasi tersebut tidak menarik.

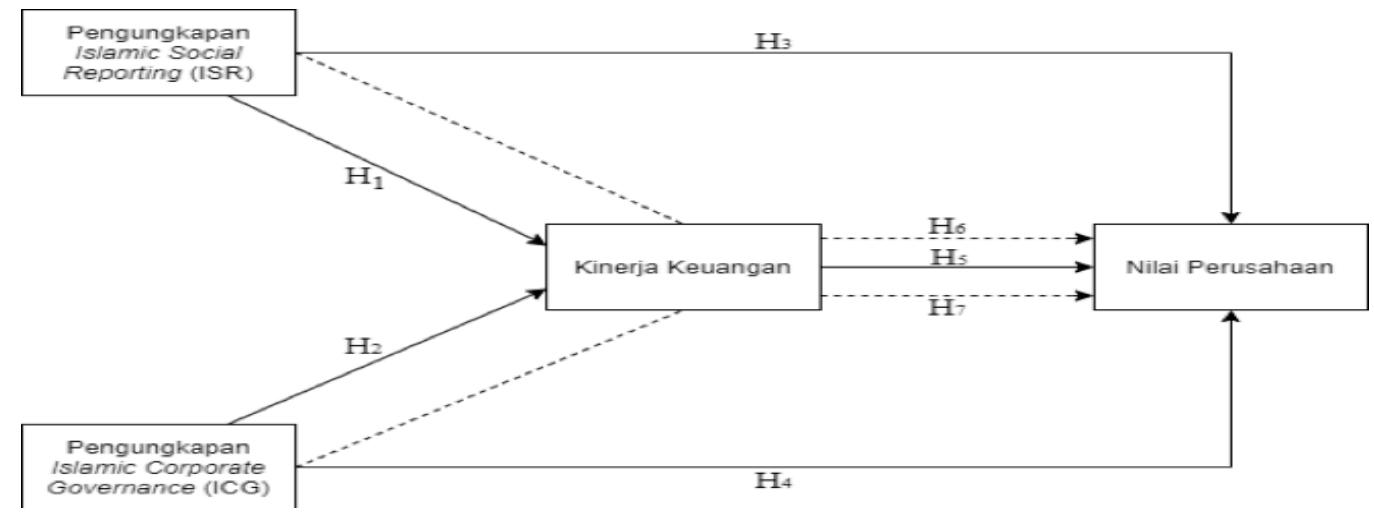

Gambar 1. Kerangka Penelitian 
Tobin's Q $=\frac{\mathrm{MVE}+\mathrm{L}}{\mathrm{A}} \quad \ldots(4)$

Keterangan:

MVE = Market Value Equity

L $\quad=$ Total Liabilitas

A $\quad=$ Total Aset

Terdapat dua variabel independen yang digunakan dalam penelitian ini, yaitu ISR. Pengukuran variabel ISR dilakukan dengan berlandaskan pada ISR Index yang dalam hal ini menggunakan metode analisis konten terhadap terhadap annual report dan kemudian dilakukan penilaian (scoring) atas item-item tersebut. Nilai 1 akan diberikan untuk setiap item yang dipaparkan dan nilai 0 diberikan untuk item yang tidak dipaparkan pada laporan tahunan.

Indeks ISR $=\frac{\text { Total Score Disclosure yang Dipenuhi }}{\text { Jumlah Skor Maksimum }} \times 100 \% \ldots$ (5)

Pengukuran variabel ICG dilakukan dengan menggunakan ICG Index yang menggunakan metode analisis konten (content analysis) terhadap terhadap laporan tahunan (annual report) kemudian memberikan penilaian (scoring) atas item-item tersebut. Nilai 1 akan diberikan untuk setiap item yang disajikan dan nilai 0 diberikan untuk item yang tidak disajikan dalam laporan tahunan.

Indeks ICG $=\frac{\text { Total Score Disclosure yang Dipenuhi }}{\text { Jumlah Skor Maksimum }} \times 100 \% \quad \ldots$ (6)

Variabel mediasi dalam penelitian ini yakni kinerja keuangan yang merupakan hasil akhir dari kemampuan manajemen perusahaan dalam jangka periode tertentu. Kinerja keuangan menjadi suatu indikator untuk menilai tingkat keberhasilan perusahaan dalam menjalankan aktivitasnya. Pengukuran kinerja keuangan dapat dilakukan dengan analisis keuangan. Pada penelitian ini, dilakukan pengukuran kinerja keuangan memakai rasio keuangan profitabilitas dengan proksi ROA.

ROA $=\frac{\text { Laba Setelah Pajak }}{\text { Total Aset }}$

\section{HASIL DAN PEMBAHASAN}

Analisis statistik deskriptif mendeskripsikan atau menggambarkan obyek yang diteliti yaitu berupa nilai minimum, nilai maximum, nilai mean, dan nilai standar deviasi. Berikut ialah hasil dari analisis statistik deskriptif dengan bantuan program SPSS 25. Hasil dan pembahasan memuat jawaban atas pertayaan penelitian, disajikan dalam bentuk diskusi/dialogis. Apabila ada tabel atau gambar, disajikan beserta interpretasi atas tabel dan gambar.

Tabel 1. Hasil Analisis Statistik Deskriptif

\begin{tabular}{cccccc}
\hline & N & Min & Max & Mean & Std. Dev \\
\hline ISR & 50 & 0,3954 & 0,7674 & 0,5847 & 0,0929 \\
ICG & 50 & 0,5000 & 0,7969 & 0,6844 & 0,0550 \\
ROA & 50 & 0,0002 & 0,1360 & 0,0215 & 0,0306 \\
Tobin's Q & 50 & 0,8478 & 3,4887 & 1,6760 & 0,7185 \\
\hline
\end{tabular}


Tabel 1 memperlihatkan bahwa nilai minimum variabel ISR adalah 0.39535, di mana nilai terendah ini dimiliki oleh Bank BRI Syariah pada 2015. Selain itu, nilai tertinggi atau maximum dari ISR menunjukkan angka 0.76744 terdapat pada Bank Syariah Mandiri pada 2019. Besar perbedaan nilai ISR antar perusahaan sampel ditunjukkan melalui standard deviasi yaitu sebesar 0.09291. Sedangkan, ISR memiliki nilai rata-rata 0.58465 yang mengungkap makna data ISR yang diungkapkan oleh sampel Bank Umum Syariah pada riset yang telah dilaksanakan lebih tinggi atau lebih besar dari standar deviasi merupakan representasi yang baik dari keseluruhan data ISR Index.

Variabel ICG pada Tabel 1 memperlihatkan nilai yang paling rendah sebesar 0.50000, yaitu ditemui pada Bank BRI Syariah pada 2015. Bank Muamalat Indonesia tahun 2016 dengan nilai sebesar 0.79688 menjadi nilai maximum dari variabel ICG. Besar perbedaan nilai ICG antar perusahaan sampel ditunjukkan oleh standar deviasi yaitu sebesar 0.05495. Sementara nilai mean dari variabel ICG adalah 0.68438 yang memiliki makna bahwa pengungkapan ICG oleh Bank Umum Syariah sebagai spesimen dari riset yang telah dilaksanakan lebih besar daripada standar deviasi. Dengan begitu, hal ini merupakan representasi baik dari keseluruhan data ICG Index.

Variabel Tobin's Q menunjukkan bahwa nilai minimum Bank Umum Syariah pada riset yang telah dilaksanakan ini adalah 0.84782. Lalu, nilai terendah atua nilai minimum ini berasal dari Bank Mega Syariah pada 2016. Selain itu, nilai maksimumnya adalah sebanyak 3.48871 yang ditemukan pada Bank BPD NTB Syariah tahun 2016. Besar standar deviasi yaitu 0.71852. Sedangkan nilai mean dari Tobin's Q yakni sebanyak 1.67600 yang memiliki makna bahwa nilai Tobin's Q dari Bank Umum Syariah yang merupakan sampel dari riset yang telah dilaksanakan ini cenderung baik karena nilai rata-rata Tobin's $Q$ sudah diatas 1 (Tobin's $Q \geq 1$ ).

Variabel ROA mempunyai nilai minimum atau nilai terendah yang tercatat yakni 0.00020 berasal dari Bank Syariah Bukopin pada 2017 dan 2018. Nilai paling tinggi atau nilai maximum dari variabel ROA adalah 0.13600 terdapat pada Bank BTPN Syariah tahun 2019. Standar deviasi dari variabel ROA menunjukkan nilai 0.03061 . Sedangkan nilai mean variabel ROA yakni sebanyak 0.02152 yang berarti nilai ROA pada perusahaan sampel dalam penelitian ini kurang baik dikarenakan oleh nilai rata-rata ROA yang dihasilkan kurang dari $1(\mathrm{ROA} \leq 1)$.

\subsection{Uji Korelasi dan Pengujian Model Regresi}

Tabel 2.

Hasil Uji Korelasi Pearson

\begin{tabular}{llrrrr}
\hline & & \multicolumn{1}{c}{ ISR } & \multicolumn{1}{c}{ ICG } & \multicolumn{1}{c}{ ROA } & \multicolumn{1}{c}{ Tobin's Q } \\
\hline ISR & Pears. & 1 & $.426^{* *}$ & $-.287^{*}$ & .043 \\
& Sig. & & .001 & .022 & .383 \\
& $\mathrm{~N}$ & 50 & 50 & 50 & 50 \\
\hline ICG & Pears. & $.426^{* *}$ & 1 & .110 & -.106 \\
& Sig. & .001 & & .224 & .232 \\
& $\mathrm{~N}$ & 50 & 50 & 50 & 50 \\
\hline ROA & Pears. & $-.287^{*}$ & .110 & 1 & $.318^{*}$ \\
& Sig. & .022 & .224 & & .012 \\
& $\mathrm{~N}$ & 50 & 50 & 50 & 50 \\
\hline Tobin' & Pears. & .043 & -.106 & $.318^{*}$ & 1 \\
s Q & Sig. & .383 & .232 & .012 & \\
& $\mathrm{~N}$ & 50 & 50 & 50 & 50 \\
\hline$* *$. & Correlation is significant at the 0.01 level (1-tailed). &
\end{tabular}


Analisis korelasi bertujuan guna mendapatkan deskripsi korelasi antar variabel yang termuat pada model riset yang telah dilaksanakan ini. Nilai keterkaitan antara ISR dengan ICG dapat dilihat pada tabel hasil uji korelasi dibawah ini, yakni menunjukkan angka 0.426 dan bernilai signifikan pada taraf $a=0.01$ karena memiliki nilai sig. 0.001 kurang dari 0.01 .

Setelah lolos dari uji asumsi klasik yang terdiri dari uji normalitas, multikolinearitas, autokorelasi, dan heteroskedastisitas, maka selanjutnya dilakukan uji regresi dan pengujian jalur pada tiap-tiap model regresi. Model 1 pada gambar 1 menjelaskan hubungan kausal antara variabel independent terhadap variabel mediasi atau variabel ISR $\left(\mathrm{X}_{1}\right)$ dan ICG $\left(\mathrm{X}_{2}\right)$ terhadap ROA $(\mathrm{Z})$. Berdasarkan persamaan regresi 8 , ISR pada ROA menunjukkan nilai $t$ hitung $>\mathrm{t}$ tabel $(-2.739>$ 1.67793). Hal ini menandakan bahwa ada pengaruh negatif yang signifikan antara ISR pada ROA. Adanya pengungkapan aktivitas riba yang menjadikan masyarakat bisa jadi beranggapan bahwa Bank Umum Syariah tidak jauh berbeda dengan bank konvensional, dan pengimplementasian ISR yang masih bersifat sukarela yang menjadikan Bank Umum Syariah belum konsisten menerapkan ISR. Hal ini meneguhkan orientasi perbankan syariah yang cenderung kapitalis (Kamla, 2009b). Hasil riset ini mendukung riset sebelumnya yang menyatakan bahwasanya pengungkapan ISR memberi pengaruh negatif dan signifikan pada kinerja keuangan dari perbankan syariah (Ananda, 2020; Nursyarifah, 2017; Nasution, 2018).

Sedangkan ICG pada ROA menampilkan hasil dari nilai t hitung sejumlah 1.906 $>$ 1.67793. Sehingga hal ini dapat menjadi bukti adanya pengaruh yang signifikan antara ICG pada ROA dengan arah yang positif. Praktik ICG yang dianggap sebagai praktik yang baik direfleksikan melalui kesesuaian operasional perbankan terhadap hukum dan prosedur yang berlaku serta ketaatannya pada prinsip-prinsip syariah. Dengan demikian, roda usaha yang dijalankan oleh perusahaan dapat terlaksana baik dan berdampak pada peningkatan kinerja keuangan perusahaan. Contohnya yakni komponen primer tata kelola lembaga syariah yang berbeda dengan tata kelola lembaga konvensional adalah adanya Dewan Pengawas Syariah (DPS). Keberadaan serta kedudukan dari DPS ini yakni berfungsi mengawasi kegiatan perbankan syariah terkait dengan aspek kepatuhan syariah. Hal ini tentu sangat penting, dikarenakan tingginya kinerja keuangan perbankan syariah tidak akan bernilai apabila tidak sesuai dengan perspektif hukum Islam. Hasil riset ini selaras dengan hasil penelitian sebelumnya dengan hasil bahwa implementasi dan pengungkapan ICG punya pengaruh signifikan positif pada kinerja keuangan perbankan syariah (Ananda, 2020; Yadiat dkk, 2017).

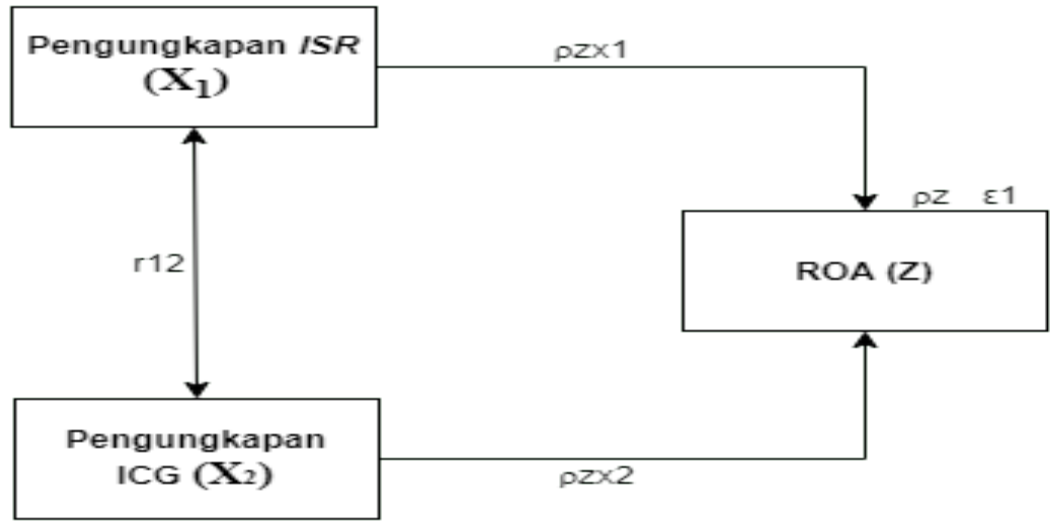

Gambar 1. Analisis Jalur Model I 
Tabel 3. Hasil Uji Regresi Model I

\begin{tabular}{lccccc}
\hline \multirow{2}{*}{ Model } & \multicolumn{2}{c}{ Unstd. } & Std. & \multirow{2}{*}{ t } & Sig. \\
& $\mathrm{B}$ & Std. Eror & Beta & & .876 \\
(Const) & -.008 & .052 & & -.157 & .876 \\
ISR & -.134 & .049 & -.408 & -2.739 & .009 \\
ICG & .158 & .083 & .284 & 1.906 & .036 \\
\hline
\end{tabular}

a. Dependent Variable: ROA

Persamaan: $Z=-0.408 \mathrm{X}_{1}+0.284 \mathrm{X}_{2}+\rho Z \varepsilon 1$

Hubungan kausal yang dijelaskan pada model 2 di gambar 2 adalah antara variabel independen yakni variabel ISR $\left(\mathrm{X}_{1}\right)$ sekaligus ICG $\left(\mathrm{X}_{2}\right)$ pada variabel dependen yakni Tobin's $\mathrm{Q}$ atau pada riset ini disimbolkan sebagai $(\mathrm{Y})$.

Berdasarkan persamaan 9 uji regresi antara ISR pada Tobin's Q menunjukkan nilai sig. $0.502>0.05(\mathrm{a}=5 \%)$. Dengan demikian, dibuktikan bahwa ada pengaruh positif namun tidak signifikan antara ISR pada nilai perusahaan. Hasil riset yang telah dilakukan relevan dengan Teori Stakeholders yang menyatakan perusahaan beroperasi dan berorientasi untuk memberikan keuntungan bagi stakeholders, dalam hal ini investor, sehingga mengamini orientasi materialistis dari perbankan syariah (Kamla, 2015). Adanya pengungkapan ISR yang tinggi akan disambut baik oleh shareholders. Jadi mampu memberi daya tarik yang berupa afeksi investor agar mau menanamkan modal pada perusahaan yang melaksanakan ISR yang pada akhirnya berdampak pada meningkatnya nilai bank syariah. Hal ini berbeda dari riset yang dilaksanakan oleh peneliti sebelumnya dengan menyatakan bahwasanya pengungkapan ISR tidak bisa menambah nilai perusahaan (Wahyuni, Pujiharto, \& Rahayu, 2020). Namun, riset ini selaras dengan hasil riset sebelumnya yang menjabarkan bahwasanya pengungkapan ISR memiliki korelasi positif pada nilai bank Syariah (Setiawan dkk, 2018; Imaniah, 2018).

Sedangkan pengaruh antara ICG pada Tobin's Q menampilkan hasil nilai sig. $0.346>0.05(a=5 \%)$. Oleh karenanya, dapat diketahui pengaruh tidak signifikan terjadi pada ICG dengan nilai perusahaan. Hasil riset ini mendukung hasil riset sebelum ini yang menyebutkan tidak ada pengaruh signifikan antara pengungkapan ICG pada nilai bank syariah (Efendi, 2020; Khasanah dkk, 2020).

Pada model 3 gambar 3 menunjukkan hubungan kausal terjadi antara variabel ISR $\left(\mathrm{X}_{1}\right)$, ICG $\left(\mathrm{X}_{2}\right)$, dan ROA $(\mathrm{Z})$ pada Tobin's $\mathrm{Q}(\mathrm{Y})$. Dalam hal ini, ROA $(\mathrm{Z})$ sebagai variabel independen juga sebagai variabel mediasi atau intervening. Berdasarkan tabel 5 hasil uji statistic, pengaruh antara ROA (Z) pada nilai perusahaan (Y) menampakkan angka sig. $0.005<0.05(a=5 \%)$. Artinya, ada pengaruh yang signifikan dan bernilai positif antara ROA pada nilai perusahaan. Entitas yang menghasilkan laba dalam jumlah besar akan menarik perhatian investor. Kenaikan ROA mengindikasikan ada prospek yang bagus dan bisa memberi pengaruh pada harapan investor atas yield yang mungkin dihasilkan dari hasil investasi investor. $\mathrm{Hal}$ inilah yang memicu peningkatan nilai perusahaan di mata para investor. Hasil riset ini selaras dengan riset yang dilaksanakan oleh peneliti sebelumnya yang menegaskan bahwasanya ada pengaruh signifikan dan bertanda positif yang terjadi pada kinerja keuangan dengan nilai perusahaan (Ibrahim dkk, 2019; Khasanah, 2020). 


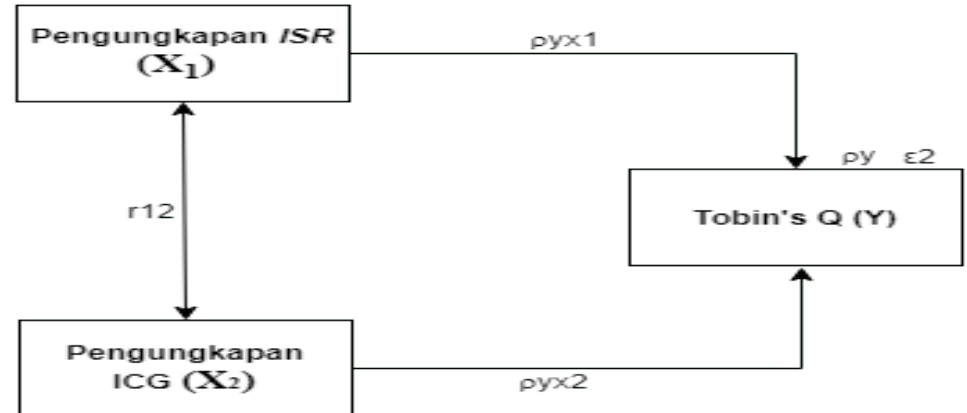

Gambar 2. Analisis Jalur Model II

Tabel 4. Hasil Uji Regresi Model II

\begin{tabular}{lrcccc}
\hline \multirow{2}{*}{ Model } & \multicolumn{2}{c}{ Unstd. } & Std. & \multirow{2}{*}{$\mathrm{t}$} & \\
& $\mathrm{B}$ & Std. Eror & Beta & $\mathrm{Sig}$ \\
\hline (Const) & 2.547 & 1.301 & & 1.958 & .056 \\
ISR & .835 & 1.234 & .108 & .677 & .502 \\
ICG & -1.986 & 2.086 & -.152 & -.952 & .346 \\
\hline
\end{tabular}

a. Dependent Variable: Tobin's Q

Persamaan: $\mathrm{Y}=0.108 \mathrm{X}_{1}-0.152 \mathrm{X}_{2}+\rho \mathrm{y} \varepsilon 1$

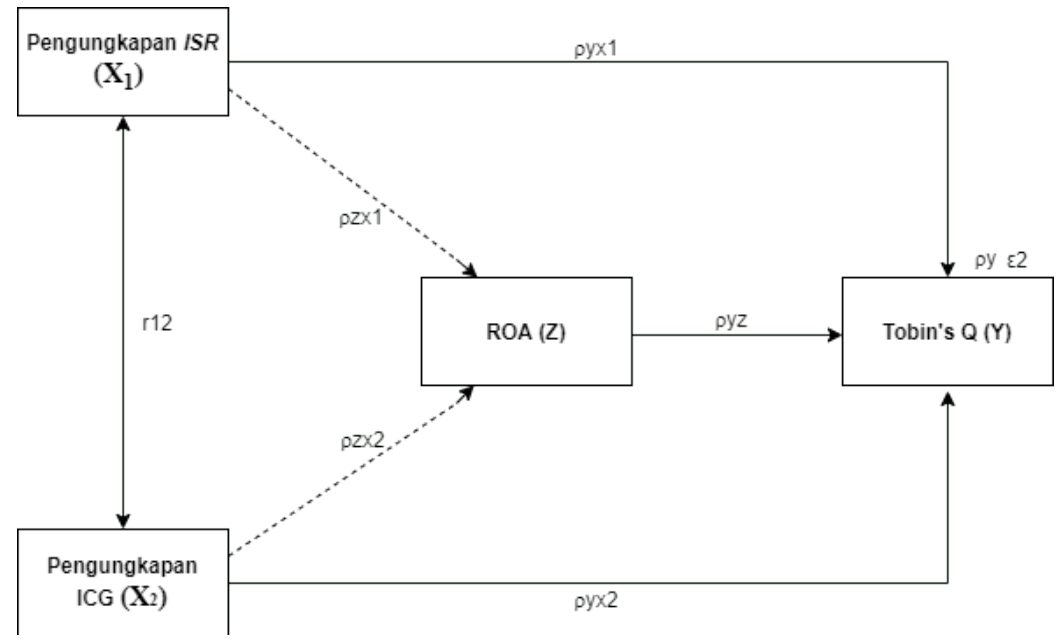

Gambar 3. Analisis Jalur Model III

Tabel 5. Hasil Uji Regresi Model III

\begin{tabular}{|c|c|c|c|c|c|}
\hline \multirow{2}{*}{ Model } & \multicolumn{2}{|c|}{ Unstd. } & \multirow{2}{*}{$\begin{array}{l}\text { Std. } \\
\text { Beta }\end{array}$} & \multirow{2}{*}{$t$} & \multirow[b]{2}{*}{ Sig. } \\
\hline & B & Std. Eror & & & \\
\hline (Const) & 2.628 & 1.205 & & 2.181 & .034 \\
\hline ISR & 2.188 & 1.231 & .283 & 1.778 & .082 \\
\hline ICG & -3.578 & 2.006 & -.274 & -1.784 & .081 \\
\hline ROA & 10.077 & 3.401 & .429 & 2.963 & .005 \\
\hline
\end{tabular}

a. Dependent Variable: Tobin's Q

Persamaan: $\mathrm{Y}=0.283 \mathrm{X}_{1}-0.274 \mathrm{X}_{2}+0.429 \mathrm{Z}+\rho \mathrm{y} \varepsilon 2 \ldots(10)$ 
Tabel 4. Tabel Hasil Analisis Jalur

\begin{tabular}{lc}
\hline Struktur Jalur & Koefisien Jalur \\
\hline $\mathbf{X}_{\mathbf{1}} \rightarrow \mathbf{Y}(0.283)$ & 0.283 \\
\hline $\mathbf{X} \mathbf{1} \rightarrow \mathbf{Z} \rightarrow \mathbf{Y}(-0.408 \times 0.429=-0.175)$ & -0.175 \\
\hline Pengaruh total $\mathbf{X}_{\mathbf{1}} \rightarrow \mathbf{Y}(0.283-0.175=0.108)$ & 0.108 \\
\hline $\mathbf{X}_{\mathbf{2}} \rightarrow \mathbf{Y}(-0.274)$ & 0.274 \\
\hline $\mathbf{X}_{\mathbf{2}} \rightarrow \mathbf{Z} \rightarrow \mathbf{Y}(0.284 \times 0.429=0.122)$ & 0.122 \\
\hline Pengaruh total $\mathbf{X}_{\mathbf{2}} \rightarrow \mathbf{Y}(-0.274+0.122=-0.152)$ & -0.152 \\
\hline
\end{tabular}

Hubungan pengaruh langsung dan tidak langsung ISR dan ICG pada Nilai Perusahaan dengan melalui Kinerja Keuangan dapat dilihat pada tabel 6. Hasil analisis jalur tabel 6, dapat dikemukakan bahwa besarnya pengaruh yang dihasilkan secara tidak langsung oleh ISR $\left(\mathrm{X}_{1}\right)$ pada variabel nilai perusahaan $(\mathrm{Y})$ melalui variabel kinerja keuangan $(Z)$ yakni -0.175 . Oleh karena pengaruh tidak langsung kurang dari pengaruh langsung $(-0.175<0.283)$, maka hubungan yang sebenarnya adalah langsung atau dapat dikatakan kinerja keuangan tidak bisa dijadikan sebagai perantara keterkaitan dalam hubungan yang terjadi antara ISR pada nilai perusahaan. Ini disebabkan karena ISR merupakan program jangka panjang perusahaan. Hasil riset ini tentunya selaras dengan riset yang dilaksanakan oleh beberapa peneliti terdahulu yang membuktikan bahwasanya kinerja keuangan tidak bisa menjadi mediator pengaruh pengungkapan ISR pada nilai perusahaan (Ardiyanto dkk, 2017; Ratih, 2014). Namun hasil tersebut tidak selaras dengan riset lain yang menyebut bahwasanya kinerja keuangan bisa memediasi pengaruh pengungkapan ISR pada nilai bank syariah (Patmawati, 2017).

Sedangkan pengaruh tidak langsung variabel ICG $\left(\mathrm{X}_{2}\right)$ pada nilai perusahaan $(\mathrm{Y})$ dengan melalui perantara variabel kinerja keuangan $(\mathrm{Z})$ adalah $0.122<0.274$ yaitu kurang dari pengaruh langsung, maka ROA tidak dapat menjadi mediator keterkaitan hubungan yang terjadi pada variabel independen dengan variabel dependen. Hasil ini diduga akibat praktik ICG yang diterapkan bank syariah belum kredibel dan belum dapat dijadikan sebagai konsiderasi untuk mengapresiasi nilai bank syariah. Adanya limitasi pada pengimplementasian ICG ini menjadikan bank syariah tidak dapat mengendalikan secara penuh persepsi stakeholder terhadap bank syariah itu sendiri. Hasil dari riset kali ini inkonsisten dengan riset sebelumnya yang menyebutkan bahwasanya terdapat pengaruh ICG pada nilai perusahan dengan mediasi kinerja keuangan (Patmawati, 2017). Akan tetapi, hasil dari riset yang dilaksanakan kali ini masih konsisten dan selaras dengan riset lain yang dijalankan oleh peneliti sebelumnya dengan memaparkan bahwa kinerja keuangan tidak bisa menjadi perantara pengaruh pengungkapan ICG pada nilai bank syariah (Suryani \& Handajani, 2020).

\section{SIMPULAN}

Penelitian yang telah dilakukan menyimpulkan bahwa pengungkapan ISR berpengaruh signifikan negative terhadap ROA, pengungkapan ICG memiliki pengaruh yang signifikan positif terhadap ROA. Sedangkan, pengungkapan ISR berpengaruh positif tidak signifikan terhadap nilai Bank Umum Syariah serta pengungkapan ICG berpengaruh tidak signifikan terhadap nilai Bank Umum Syariah. ROA berpengaruh positif signifikan terhadap nilai Bank Umum Syariah. Namun ROA tidak terbukti dapat menjadi perantara pengaruh pengungkapan ISR dan ICG terhadap nilai Bank Umum Syariah di Indonesia periode 2015-2019.

Akan tetapi, pada penelitian ini masih terdapat beberapa keterbatasan, yaitu: (1) Ukuran yang digunakan untuk menggambarkan kinerja keuangan hanya 
menggunakan rasio profitabilitas yang diproksikan dengan ROA, padahal masih terdapat ukuran lain yang dapat menggambarkan kinerja keuangan seperti ROE, ROI, Sharia Conformity, dll. (2) Objek yang digunakan adalah Bank Umum Syariah, dimana masih terdapat objek lain yang bisa digunakan seperti perusahaan yang terdaftar di Indeks Saham Syariah Indonesia (ISSI) atau Jakarta Islamic Index (JII) yang mempunyai cakupan sampel yang lebih luas dan aktivitas operasi yang berdampak terhadap lingkungan.

Implikasi teoretis dari penelitian ini adalah bahwa perlu suatu usaha yang lebih masif untuk mengarahkan perbankan syariah kepada tujuan dakwah dibandingkan bisnis agar konsekuensi praktiknya tidak terjebak pada kapitalisme berkedok syariah. Upaya sedemikan rupa sebenarnya telah digagas oleh beberapa akademisi muslim (misal Niswatin, Triyuwono, Nurkholis, \& Kamayanti, 2014) walau secara regulatoris belum diadopsi menjadi kebijakan.

\section{REFERENSI}

Abadi, M. T., Mubarok, M. S., \& Sholihah, R. A. (2020). Implementasi Islamic Social Reporting Index Sebagai Indikator Akuntabilitas Sosial Bank Syariah. AlInsyiroh: Jurnal Studi Keislaman, 6(1), 1-25. https://doi.org/10.35309/alinsyiroh.v6i1.3813

Ananda, C. Z., \& NR, E. (2020). Pengaruh Islamic Corporate Governance Dan Islamic Corporate Social Responsibility Terhadap Kinerja Perbankan Syariah. Jurnal Eksplorasi Akuntasi, 2(1), 2065-2082.

Ardiyanto, T., \& Haryanto, H. (2017). Pengaruh Pengungkapan Corporate Social Responsibility Terhadap Nilai Perusahaan Dengan Kinerja Keuangan Sebagai Variabel Intervening. Diponegoro Journal of Accounting, 6(4), 1-15.

Asrori. (2014). Implementasi Islamic Corporate Governance dan Implikasinya Terhadap Kinerja Bank Syariah. Jurnal Dinamika Akuntansi, 6(1), 90-102.

Dianawati, C. P., \& Fuadati, S. R. (2016). Pengaruh CSR Dan GCG Terhadap Nilai Perusahaan: Profitabilitas Sebagai Variabel Intervening. Jurnal Ilmu Dan Riset Manajemen, 5(1), 1-20.

Effendi, V. N. (2020). Pengaruh csr disclosure dan gcg terhadap nilai perusahaan dengan kinerja keuangan sebagai variabel intervening di perusahaan manufaktur yang terdaftar di bursa efek indonesia (2012-2014). Jurnal Bisnis Dan Teknologi, 12(1), 45-54.

Ibrahim, R. H., \& Muthohar, A. M. (2019). Pengaruh Komisaris Independen dan Indeks Islamic Social Reporting Terhadap Nilai Perusahaan Dengan Profitabilitas Sebagai Variabel Intervening. Jurnal Ilmiah Ekonomi Islam, 5(01), 9-20.

Imaniah, N. (2018). Pengaruh Pengungkapan Islamic Social Reporting, Profitabilitas, Dan Likuiditas Terhadap Nilai Perusahaan (Studi Empiris Pada Perusahaan Yang Terdaftar Di Jakarta Islamic Index Pada Bursa Efek Indonesia). Tesis Universitas islam Negeri Syarif Hidayatullah. Universitas Islam Negeri Syarif Hidayatullah Jakarta.

Junusi, R. El. (2012). Implementasi Syariah Governance Serta Implikasinya Terhadap Reputasi dan Kepercayaan Bank Syariah. Al-Tahrir, 12(1), 91-115.

Kamla, R. (2009a). Critical insights into contemporary Islamic accounting. Critical Perspectives on Accounting, 20(8), 921-932. https://doi.org/10.1016/j.cpa.2009.01.002

Kamla, R. (2009b). Critical Perspectives on Accounting Critical insights into contemporary Islamic accounting, 20, 921-932. https://doi.org/10.1016/j.cpa.2009.01.002

Kamla, R. (2015). Critical Muslim intellectuals' thought: Possible contributions to the development of emancipatory accounting thought. Critical Perspectives on 
Accounting, 31, 64-74. https://doi.org/10.1016/j.cpa.2015.01.014

Khasanah, I. D., \& Sucipto, A. (2020). Pengaruh corporate social responbility (csr) dan good corporate governance (gcg) terhadap nilai perusahaan dengan profitabilitas sebagai variabel intervening. AKUNTABEL: Jurnal Akuntansi Dan Keuangan, 17(1), 14-28.

Mardiani, L., Yadiati, W., \& Jaenudin, E. (2019). Islamic Corporate Governance Dan Kinerja Keuangan Unit Usaha Syariah (UUS) Periode 2013-2017. Jurnal Akuntansi: Kajian Ilmiah Akuntansi (JAK), 6(2), 128. https://doi.org/10.30656/jak.v6i2.1411

Nasution, A. A. (2018). Pengaruh Shariah Compliance, IslamicCorporate Governance dan IslamicSocial Reporting Terhadap KinerjaKeuangan dengan Ukuran Perusahaansebagai Moderating pada Bank Syariah. Universitas Sumatera Utara.

Niswatin, Triyuwono, I., Nurkholis, \& Kamayanti, A. (2014). Islamic Values of Islamic Bank Underlying Performance Assessment. Research Journal of Finance and Accounting, 5(24), 106-114.

Nugroho, M. A. S. N. (2015). Urgensi Penerapan Islamic Corporate Governance Di Baitul Maal Wat Tamwil (BMT). Kajian Bisnis STIE Widya Wiwaha, 23(1), 64-70. https://doi.org/10.32477/jkb.v23i1.204

Nursyarifah, H. O. (2017). Pengaruh DPK, FDR, dan ISR Terhadap Kinerja Keuangan Perbankan Syariah Indonesia Tahun 2010-2015.

Patmawati. (2017). Pengaruh Corporate Social Responsibility Dan Good Corporate Governance Terhadap Nilai Perusahaan dengan Kinerja Keuangan sebagai Variabel Intervening. Jurnal Ilmiah Ekonomi Global Masa Kini, 8(2089-6018), 4858.

Ratih, S., \& Setyarini, Y. (2014). Pengaruh Good Corporate Governance (Gcg) Dan Corporate Social Responsibility (Csr) Terhadap Nilai Perusahaan Dengan Kinerja Keuangan Sebagai Variable Intervening Pada Perusahaan Pertambangan Yang Go Public Di Bei. AKRUAL: Jurnal Akuntansi, 5(2), 115. https://doi.org/10.26740/jaj.v5n2.p115-132

Retnaningsih, S., Hariyanti, W., \& Astuti, T. P. (2019). Pengaruh Pengungkapan Islamic Social Reporting (ISR) Terhadap Kinerja Keuangan Pada Perbankan Syariah Di Indonesia Tahun 2012-2016. AKTSAR: Jurnal Akuntansi Syariah, 2(2), 169. https://doi.org/10.21043/aktsar.v2i2.5850

Setiawan, I., Swandari, F., \& Dewi, D. M. (2018). Pengaruh Pengungkapan Islamic Social Reporting (Isr) Terhadap Nilai Perusahaan Dengan Kinerja Keuangan Sebagai Variabel Moderating. JWM (Jurnal Wawasan Manajemen), 6(2), 168186. https://doi.org/10.20527/jwm.v6i2.150

Setiawati, L. W., \& Lim, M. (2018). Analisis Pengaruh Profitabilitas, Ukuran Perusahaan, Leverage, Dan Pengungkapan Sosial Terhadap Nilai Perusahaan Pada Perusahaan Manufaktur Yang Terdaftar Di Bursa Efek Indonesia Periode 2011-2015. Jurnal Akuntansi, $12(1), \quad$ 29-57. https://doi.org/10.25170/jara.v12i1.57

Suryani, C., \& Handajani, L. (2020). Factors Affecting The Value Of Companies With Profitability As Intervening Variables. E-JURNAL AKUNTANSI, 3O(7), 1857-1871.

tirto.id. (2020). Perbankan Dikuasai Konvensional, RI Perlu Bank Syariah Skala Besar.

Utami, R., \& Yusniar, M. W. (2020). Pengungkapan Islamic Corporate Social Responsibility (Icsr) Dan Good Corporate Governance (Gcg) Terhadap Nilai Perusahaan Dengan Kinerja Keuangan Sebagai Variabel Intervening). EL Muhasaba Jurnal Akuntansi, 11(2), 162-176. https://doi.org/10.18860/em.v1 1i2.8922 
Wahyuni, S., Pujiharto, \& Rahayu, D. R. (2020). Islamic corporate governance index and Islamic social reporting disclosure index for enhancing firm value: An empirical study of Islamic banking in Indonesia. International Journal of Innovation, Creativity and Change, 12(1), 511-520.

Wibowo, S., Yokhebed, \& Tampubolon, L. D. (2016). Pengaruh csr disclosure dan gcg terhadap nilai perusahaan dengan kinerja keuangan sebagai variabel intervening di perusahaan manufaktur yang terdaftar di bursa efek indonesia (2012-2014). In Prosiding Seminar Nasional Multi Disiplin Ilmu \& Call For Papers Unisbank (Sendi_U) KE-2 (pp. 926-935).

Yadiat, W., Gustani, \& Amrania, G. (2017). The effect of Islamic Corporate Governance (ICG) and Islamic Corporate Social Responsibility (ICSR) disclosures on market discipline with financial performance used as intervening variables (Empirical Study on Shariah based Banks Operating in QISMUT Count. International Journal of Applied Business and Economic Research, 15(24), 119141. 